\title{
44. PALEOENVIRONMENTAL IMPLICATIONS OF THE MAGNETIC CHARACTERISTICS OF SEDIMENTS FROM DEEP SEA DRILLING PROJECT SITE 514, SOUTHEAST ARGENTINE BASIN ${ }^{1}$
}

\author{
Jan Bloemendal, University of Liverpool, Department of Geography, Liverpool L69 3BX, United Kingdom
}

\begin{abstract}
This chapter demonstrates the stratigraphic application of measurements of magnetic susceptibility and related parameters to the sediment record at Site 514. The work identifies two periods characterized by pronounced fluctuations in magnetic mineral concentration and in magnetic hardness: from 0 -ca. $0.75 \mathrm{Ma}(0$-ca. $10 \mathrm{~m}$ sub-bottom) and from ca. 2.6-3.0 Ma (ca. 60-90 m sub-bottom). The fluctuations are tentatively ascribed to changes in current paleovelocity effecting periods of relative concentration of magnetic minerals. Comparison of the inferred record of current paleovelocity at Site 514 with that from a site in the Vema Channel, South Atlantic, suggests some accordance.

An attempt is made to express the susceptibility data in terms of an accumulation rate using the age-depth data available for the site. The results suggest a major reduction in the rate of deposition of magnetic minerals after ca. 2.5 Ma (ca. $45 \mathrm{~m}$ sub-bottom).

Finally, changes in the intensity of Natural Remanent Magnetization (NRM) at the site are clearly shown to be controlled by changes in magnetic concentration and mineralogy rather than by changes in the intensity of the geomagnetic field. Attempts to normalize the NRM record using several magnetic parameters were unsuccessful.
\end{abstract}

\section{INTRODUCTION}

Previous studies of the magnetic characteristics of marine sediments have focused almost entirely on their record of Natural Remanent Magnetization (NRM). This is due to the interest in obtaining continuous records of geomagnetic field behavior in the geologic past and to the need for establishing a chronostratigraphic framework for other aspects of marine sedimentology based on polarity-reversal stratigraphies. Detailed and systematic work on the mineral magnetic (i.e., non-naturally remanent or "induced" magnetization) properties of marine sediments has been relatively neglected, however. When such studies have been carried out, they have generally been of two kinds-namely, those intended to aid interpretation of the NRM record, particularly in order to determine whether or not this is of a detrital or an in situ chemical origin (e.g., Haggerty, 1970; Kent and Lowrie, 1974) and, secondly, studies of paleocurrent directions and intensities (e.g., Hamilton, 1979; Ellwood, 1980). There are few examples of magnetic studies of marine sediments whose explicit aim has been to interpret the changing concentrations and types of magnetic minerals with relation to changing sediment sources and processes of deposition.

The present study of sediments from DSDP Site 514, Southeast Argentine Basin, has two main objectives: (1) to demonstrate how a number of simple and rapidly measured magnetic parameters indicative of changing magnetic mineral concentrations and types can be used to yield a potentially valuable stratigraphy for marine sediments; (2) to interpret the derived stratigraphy in paleoenvironmental terms and, more briefly, to con-

\footnotetext{
${ }^{1}$ Ludwig, W. J., Krasheninnikov, v. A., et al., Init. Repts. DSDP, 71: Washington (U.S. Govt. Printing Office).
}

sider its implications for the interpretation of the NRM record for this site. The rationale behind this approach originated in suggestions of the potential value of magnetic susceptibility as a stratigraphic tool for marine sediments (Radhakrishnamurty et al., 1968; Amin et al., 1972; Somayajulu et al., 1975) as well as in recent illustrations of the application of mineral magnetic measurements to studies of fluvial and lacustrine sediments (e.g., Oldfield et al., 1978, 1979).

\section{SAMPLING AND MEASUREMENT}

The hydraulic piston cored 150.8-meter sequence of predominantly diatomaceous clays and muddy diatomaceous oozes of early Pliocene (Gilbert Epoch) to Recent age was sampled aboard the Glomar Challenger by carefully pushing plastic cylinders of $10-13 \mathrm{cc}$ volume into the split core sections. After removal, the ends were sealed with adhesive tape and the cylinders stored in plastic containers to reduce dehydration. We obtained 473 samples. The NRM of half the samples was measured with a Digico computerized single-sample spinner magnetometer. Subsequently, the NRM of all the samples was measured at the Department of Geophysics, University of Edinburgh, U. K., using similar instrumentation. The results of these measurements are given by Salloway (this volume). After we completed NRM measurements, three other kinds of magnetic measurements were performed: (1) Low-field magnetic susceptibility. This was measured on a portable battery-powered meter manufactured by G. W. Bartington of Littlemoor Scientific Instruments, Oxford, U. K. The sensitivity of this instrument $\left(\sim 1 \times 10^{-7} \mathrm{G} \mathrm{Oe}^{-1}\right)$ is substantially higher than most comparable commercially available bridges. (2) Anhysteretic Remanent Magnetization (ARM). After demagnetization at $1 \mathrm{kOe}$ to remove the NRM, ARMs were grown in a peak alternating field (AF) of $1 \mathrm{kOe}$ with a DC field of 0.4 Oe superimposed, the DC field being applied parallel to the axis of the coil generating the AF. The ARMs were measured on a computerized parastatic magnetometer at the Department of Geophysics, University of Liverpool, U. K. Selected samples were then subjected to partial-stepwise AF demagnetization using a twoaxis tumbler. (3) Isothermal Remanent Magnetization (IRM). Selected samples were given an IRM in a field of $1 \mathrm{kOe}$ (using a conventional electromagnet), measured, and demagnetized as for ARM. All of the samples were then given an IRM in a field of $10 \mathrm{kOe}$. For convenience, this is referred to as "saturation" IRM (SIRM), although it is understood that the magnetization of many of the samples may not have 
been completely saturated. After measurement of SIRM, the samples were placed in a reversed field of $1 \mathrm{kOe}$ to obtain the parameter " $S$," or $S$-ratio, defined as - BACK IRM 1000 /SIRM (Thompson, 1980). Finally, selected samples were placed in successive reversed fields of increasing strength and the change in IRM measured at each stage in order to obtain the coercivity of SIRM $\left(H_{c r}\right)$. The $H_{c r}$ was estimated by fitting an approximating cubic spline to the IRM curve and iterating to the point of intersection of the cubic spline function with the zero remanence axis.

A combination of the measurements just described may be used to indicate changes in magnetic mineral concentrations, types, and grain sizes. Because sediments usually contain assemblages of varied types and size and shape distributions of magnetic grains, however, such changes can usually be identified only as general trends. In the case of ferrimagnets (e.g., magnetite), pseudo-single domain and fine multidomain grains exhibit increases in the ratio of SIRM to susceptibility with decreasing grain size; at the same time, $H_{c r}$ increases. Coarse multidomain grains and grains on the stable single-domain/superparamagnetic boundary exhibit a low SIRM/susceptibility ratio and low $H_{c r}$. A pure assemblage of ultrafine (superparamagnetic) grains do not carry a stable remanence at room temperature and only contribute to susceptibility. The magnetization per unit volume of canted antiferromagnetic material (e.g., hematite) is several orders of magnitude less than that of ferrimagnets, hence hematite exhibits low susceptibility and SIRM but has high SIRM/susceptibility and high $H_{c r}$. Since even fine-grained elongated magnetite grains saturate in fields of 1-2 kOe, whereas fine-grained hematite requires much higher fields for saturation, the parameter " $S$ " (defined in the foregoing) provides a rapid method of estimating the ratio of ferrimagnetic to canted antiferromagnetic material in a sample.

\section{RESULTS}

Figures 1 and 2 show susceptibility and the intensities of NRM, ARM, and SIRM plotted against depth. Susceptibility, ARM, and SIRM are controlled by changes in magnetic mineral assemblages and concentrations, although because susceptibility is not as dependent on magnetic grain size it provides a better summary of bulk magnetic content. NRM intensity is also controlled by magnetic concentration but is highly dependent as well on changes in the grain size and mineralogy of magnetic components, the mode of remanence acquisition, and the intensity of the geomagnetic field. The obvious relationship between the downhole fluctuations of all four parameters indicates that at Site 514 NRM intensity is controlled primarily by magnetic content rather than by geomagnetic paleointensity. There is no clear association between magnetic concentration and lithology. The magnetic concentration is relatively high and fluctuates rapidly in the upper Quaternary (ca. 0-10 m sub-bot$t^{2} \mathrm{~m}^{2}$ ). It exhibits relatively uniform values through the lower Quaternary and upper Pliocene (ca. 10-60 m). Unfortunately, sampling density in this part of the section was reduced because of no recovery (Core 7 , ca. 23-28 m), pipe rust contamination, and coring disturbance. There is a series of well-resolved fluctuations in magnetic concentration in the upper part of the lower Pliocene (ca. 60-90 m), with maxima at ca. 80 and 90 meters. The magnetic concentration rises slightly into the major hiatus at ca. 111 meters (see site chapter and susceptibility record, Fig. 4) and then declines toward the base of the section.

\footnotetext{
2 All depths quoted subsequently are sub-bottom.
}

\section{Magnetic Accumulation Rates}

There are several mechanisms that may effect changes in the concentration of magnetic minerals in marine sediments. Principal among them may be (after Henshaw and Merrill, 1980) (1) change in the rate of supply of magnetic minerals from continental, volcanic, hydrothermal, or cosmic sources; (2) change in the accumulation rate of the weakly magnetic component of the sediment (e.g., microfossil tests); (3) authigenic growth of magnetic minerals and/or diagenesis of magnetic minerals to weakly magnetic forms, or vice versa; (4) change in depositional or erosional processes (e.g., winnowing) which may differentially affect the rate of supply of the sedimentary components to the sediment surface.

Interpretation of magnetic concentration changes in terms of environmental change might best be achieved by identifying the effect of each of these factors. In practice, however, this is likely to be problematical. The influence of (3) is discounted for reasons outlined in the following. Given detailed knowledge of variations in bulk sediment accumulation rate through a geological section, magnetic parameters may be expressed in terms of an accumulation rate, and by this means dilution or concentration effects through changes in the deposition rate of the weakly magnetic sediment matrix may be reduced or eliminated. This was attempted for the samples from Site 514 in the following way. A least-squares cubic spline was fitted to the age-depth data for that part of the section above the hiatus at ca. 111 meters. These data are derived from the known ages of paleomagnetic event and epoch boundaries and microfossil zone boundaries (see site chapter). Each of the data points was given equal weight, and the knots were regularly distributed between 0 and 111 meters; the resulting curve is shown in Figure 3. The fit is better below 40 meters than above. The age of the top and bottom of each of the samples was estimated by cubic spline interpolation and by this means it was possible to calculate the approximate time taken for each sample to accumulate. The volume susceptibility of each sample was then divided by this result to obtain the magnetic accumulation rate. A similar procedure was adopted for that part of the section below 111 meters, except that a linear regression line was fitted to the age-depth data. Susceptibility and magnetic accumulation rate versus time are shown in Figure 4.

Plotting susceptibility against time rather than against depth provides a more realistic presentation of the data. The record of the relatively slowly accumulated Quaternary and upper Pliocene parts of the section is expanded in relation to the much more rapidly accumulated lower Pliocene part of the section. The unsampled intervals (see Sampling and Measurement), although small in depth, represent relatively long intervals of time. Assuming no change in accumulation rate within and between peaks - though this assumption may be invalid (see following discussion)-the approximate durations of the pronounced susceptibility peaks between ca. 2.6 and 3.0 Ma were estimated from the fitted age-depth 


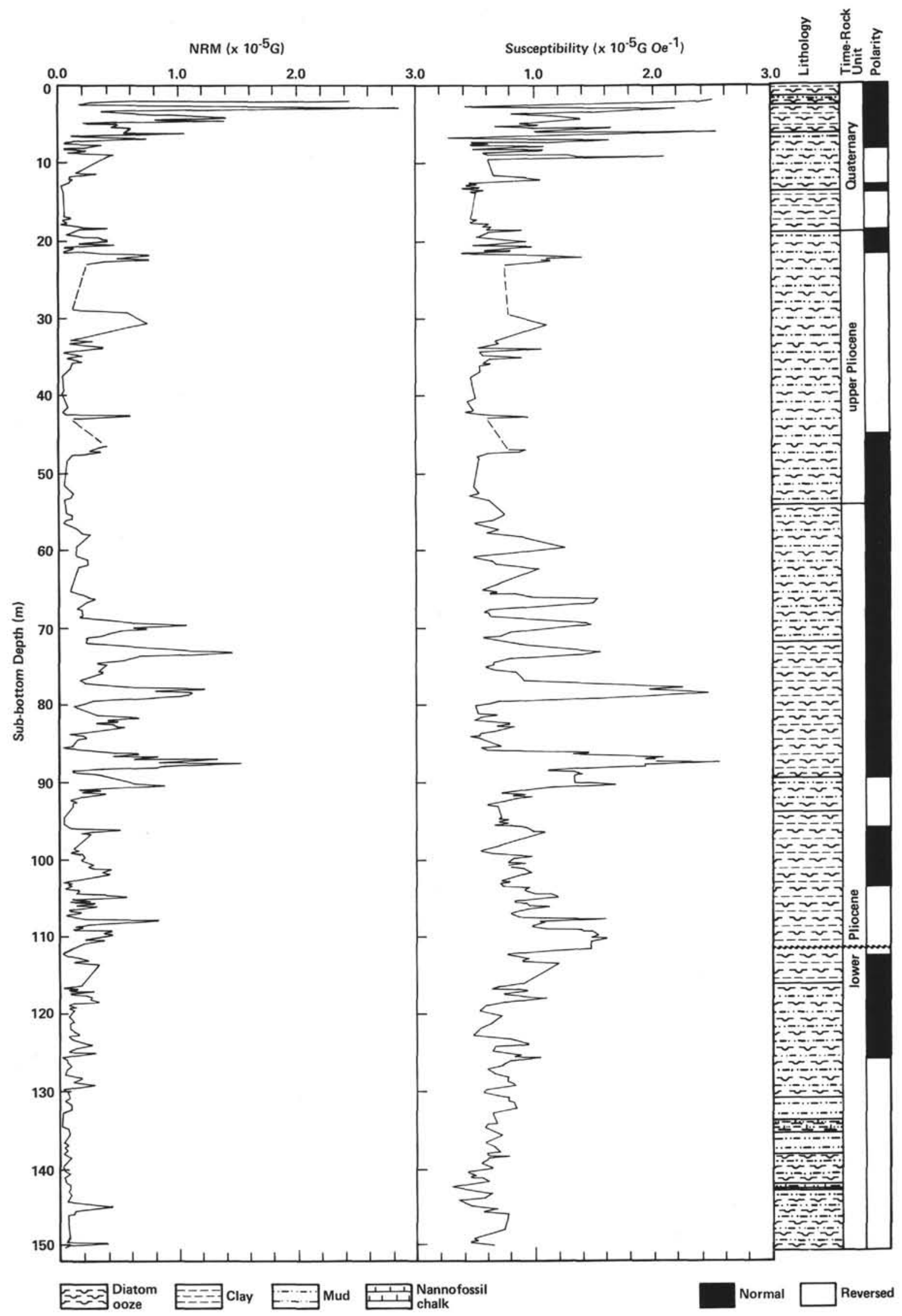

Figure 1. Downhole NRM and magnetic susceptibility. 


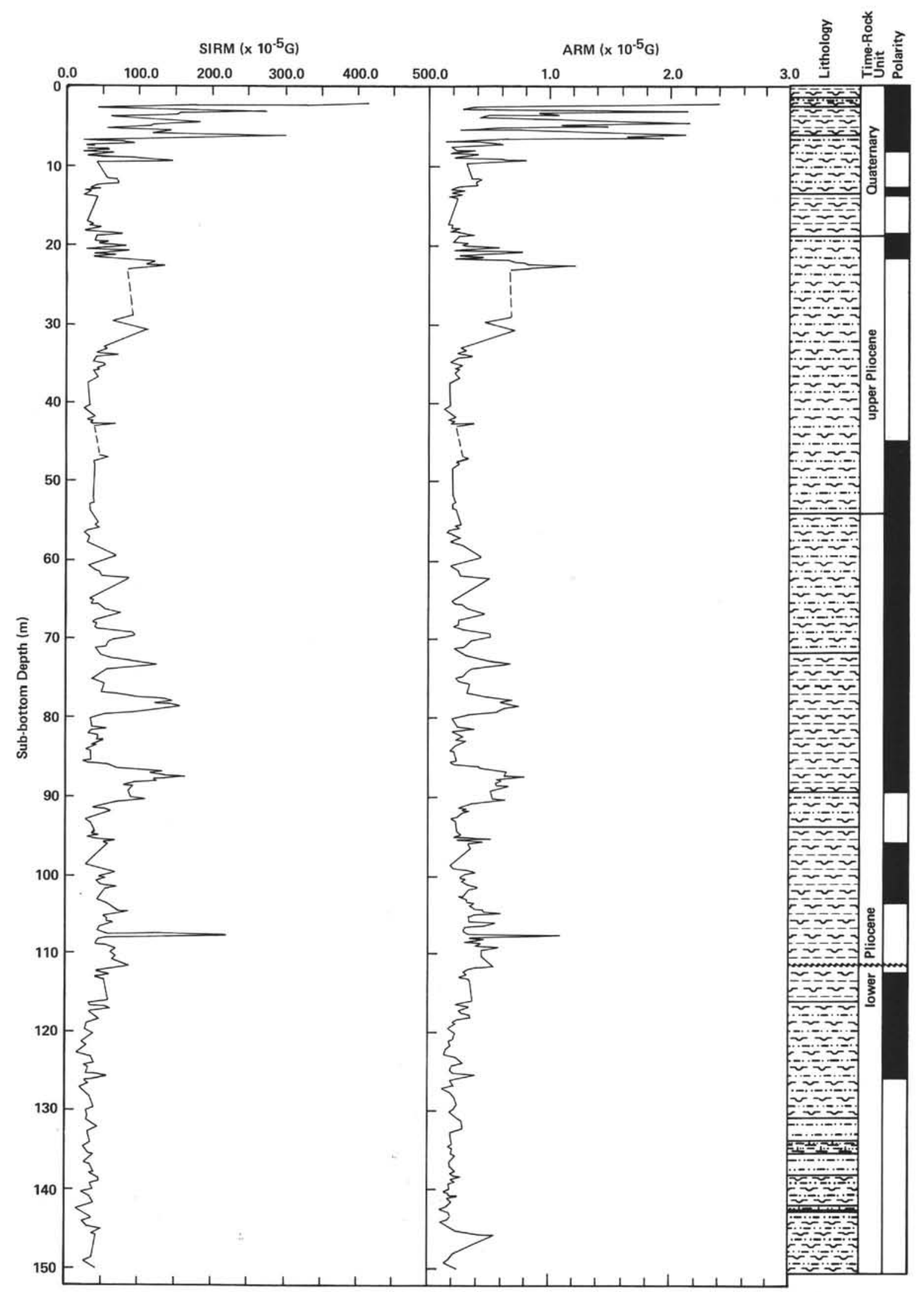

Figure 2. Downhole SIRM and ARM. Lithological symbols as for Figure 1. 


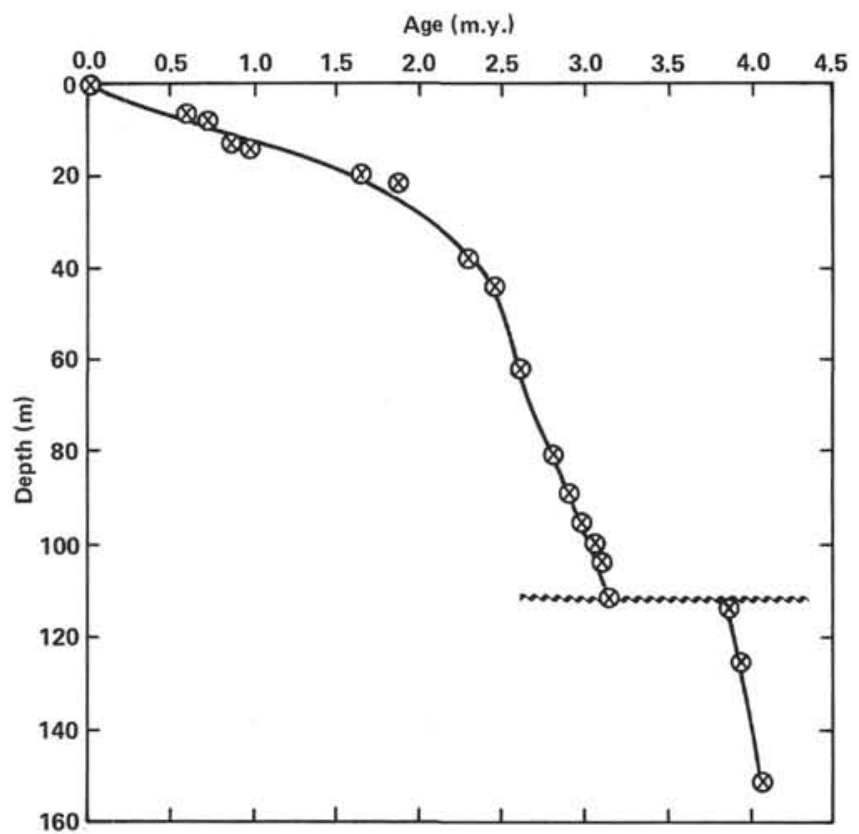

Figure 3. Fitted age-depth curve for site 514 .

curve (Fig. 3). The features have similar durations of ca. $30-60 y^{3}$. No attempt was made to estimate the durations of the susceptibility peaks in the Quaternary because the sampling density and accumulation rate over this part of the section have not permitted their adequate resolution: it is possible that some of these may comprise a number of discrete peaks.

The plot of magnetic accumulation rate (MAR) versus time shows that despite the relatively large peaks in magnetic concentration between 0 and ca. $0.75 \mathrm{Ma}$, the actual rate of supply of magnetic minerals to the sediment surface was relatively low. (Because of the poorer fit of the cubic spline function to the age-depth data for this part of the section, linear interpolation between age-depth points was used to estimate the age of the base of this interval; however, the result was almost identical). Although there are relatively long intervals of time not represented by the samples, the period from ca. 0.75 to $2.5 \mathrm{Ma}$ exhibits slightly rising MAR. MAR then rises abruptly and exhibits a pattern of fluctuations similar to that shown in the volume susceptibility record. Maximum MAR is recorded immediately below the hiatus at ca. 111 meters (ca. $3.86 \mathrm{Ma}$ ).

\section{Magnetic Mineralogy}

Figure 5 plots " $S$ ", and SIRM/susceptibility against depth. The downhole fluctuations in $S$ show a strong positive relationship with those for the parameters plotted in Figures 1 and 2 (the Pearson correlation coefficient for $S$ and susceptibility is 0.7 ), indicating that the peaks in magnetic concentration represent significant reductions in magnetic hardness. SIRM/susceptibility shows little variation below ca. 30 meters but exhibits maxima at ca. 25 meters and in the upper 10 meters of the section. Unlike the peaks in magnetic concentration between ca. 60 and 90 meters, those above 10 meters ex- hibit significant increases in SIRM/susceptibility, suggesting a rather different magnetic mineralogy.

Figure 6 shows normalized coercivity of SIRM $\left(H_{c r}\right)$ curves for selected samples from maxima and minima (Set A and Set B, respectively) in magnetic concentration. Set A exhibits $H_{c r} s$ of less than 400 Oe and almost complete back saturation at $2 \mathrm{kOe}$. The samples in Set B have $H_{c r} s$ greater than 900 Oe and are only slightly more than $50 \%$ back-saturated at $2 \mathrm{kOe}$. This suggests that they contain a larger component of either fine-grained canted antiferromagnetic material or fine, elongated ferrimagnetic grains. Figure 7 plots $S$ against $H_{c r}$ for samples from Site 514. The strong inverse relationship indicates that for these sediments, $S$ may be used as a surrogate parameter for $H_{c r}$. The relationship demonstrates that changes in magnetic hardness can be summarized by the two simple and rapid measurements needed to calculate $S$.

Figure 8 shows plots of NRM/susceptibility, NRM/ ARM, and NRM/SIRM against depth. These are significant in respect of previous attempts to obtain relative palaeointensities from lake (e.g., Levi and Banerjee, 1976) and marine (e.g. Wollin et al., 1971) sediments. Levi and Banerjee (1976) attempted to normalize the NRM for variations in the concentration of the NRM carriers, using ARM (or AF-cleaned ARM) as the normalizing parameter. It is clear from Figures 1 and 2 that the amplitude of variation in NRM intensity is considerably greater than that shown in the susceptibility, ARM, and SIRM records. Consequently the NRM/susceptibility, NRM/ARM, and NRM/SIRM plots shown in Figure 8 exhibit downhole fluctuations similar to those of NRM, indicating that for these sediments susceptibility, ARM, and SIRM are all inadequate normalizing parameters for NRM.

Figure 9 shows two examples of stepwise AF demagnetization plots for NRM, ARM, and IRM from a maximum (Sample 18-2, 48-50) and a minimum (Sample 514 $2-2,89-91 \mathrm{~cm}$ ) in magnetic concentration. The NRM demagnetizations were carried out by Salloway (this volume). The ARM was always a substantially harder magnetization than the IRM: median destructive fields (MDFs) ranged from 340 to 555 Oe for the former and from 90 to 210 Oe for the latter. For magnetic mineral assemblages dominated by magnetite or maghemite, Johnson et al. (1975) interpret such results as indicative of single-domain or pseudosingle-domain grains. Relatively few of the NRM demagnetization spectra exhibited smooth curves, and frequently an unstable component of magnetization which was removed in demagnetizing fields of 150 or 200 Oe could be seen (Salloway, personal communication). The spectrum for Sample 514 $18-2,48-50 \mathrm{~cm}$ illustrates such behavior. In general, the NRM spectra were intermediate between these for ARM and IRM in their resistance to AF demagnetization. MDFs ranged from 42 to 571 Oe $($ mean $=258$ ). This suggests that (1) the spectrum of grains carrying the NRM is different from those carrying either the IRM or the ARM and that, as concluded in the foregoing, an attempt to normalize the NRM using either of these parameters would be ill-founded; and (2) even in those 


\section{J. BLOEMENDAL}

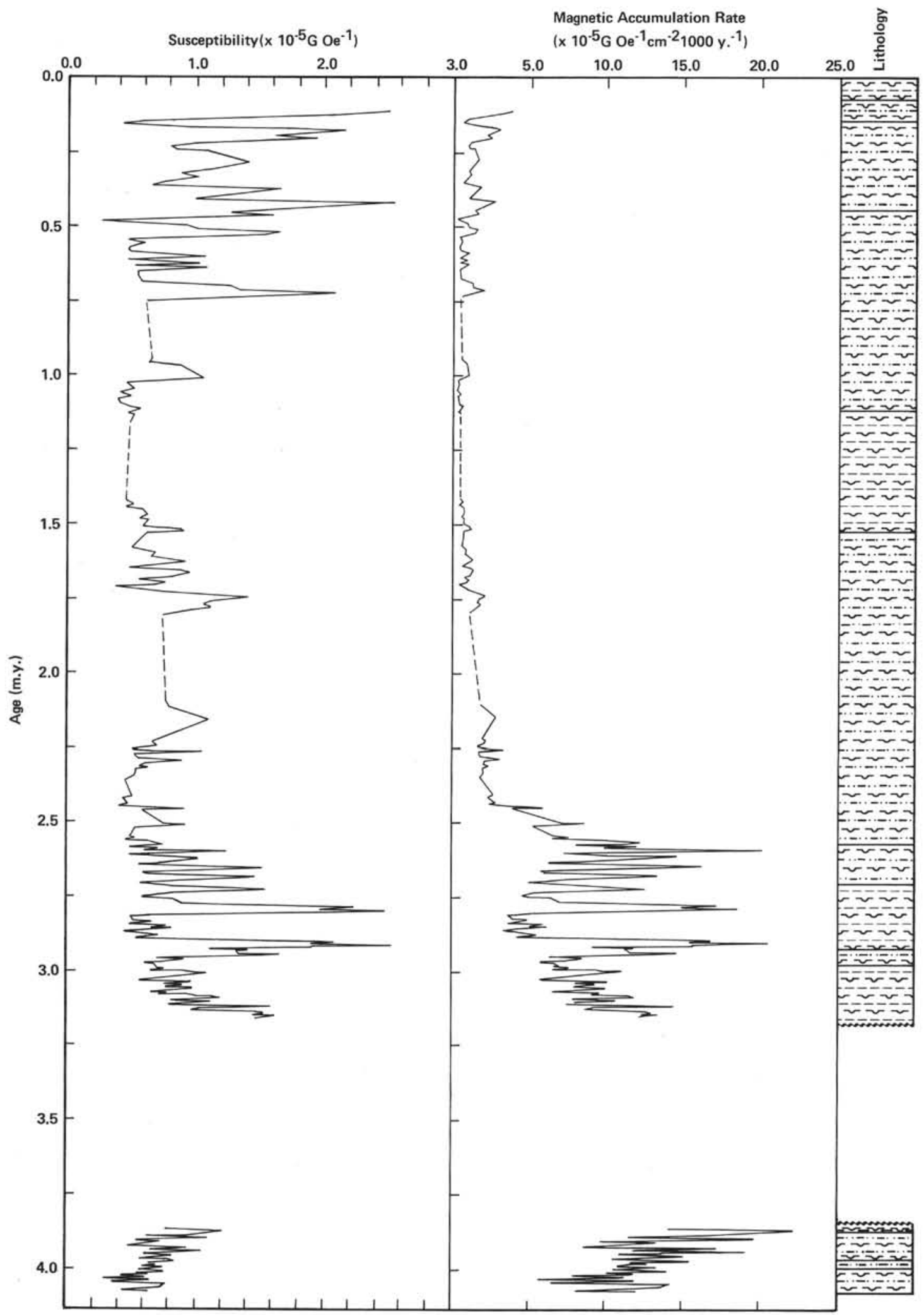

Figure 4. Magnetic susceptibility, magnetic accumulation rate, and lithological boundaries plotted against time using the age-depth curve shown in Figure 3. Lithological symbols as for Figure 1. (Only the major lithological changes are shown.) 


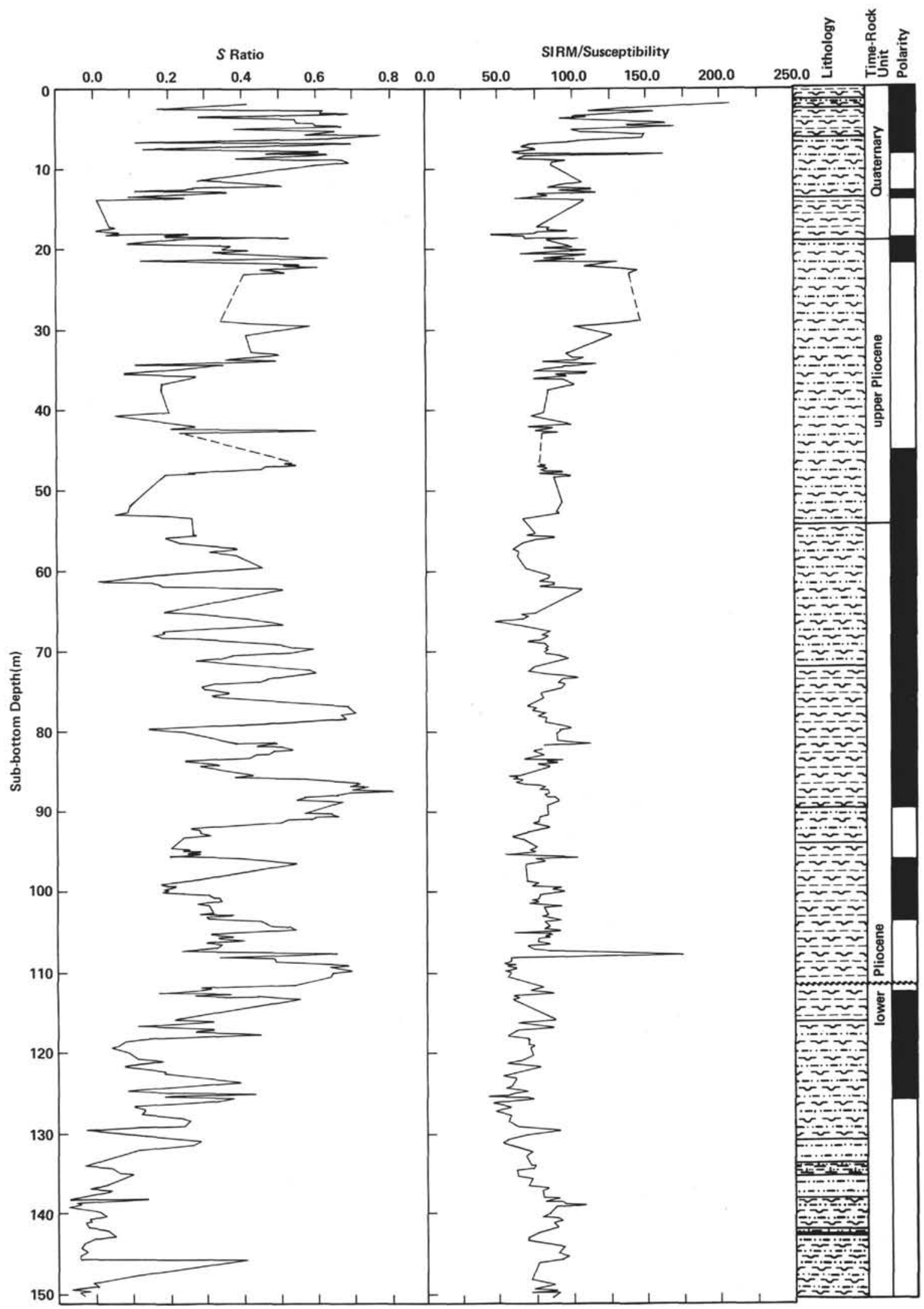

Figure 5. Downhole $S$ ratio and SIRM/susceptibility. Lithological symbols as for Figure 1. 


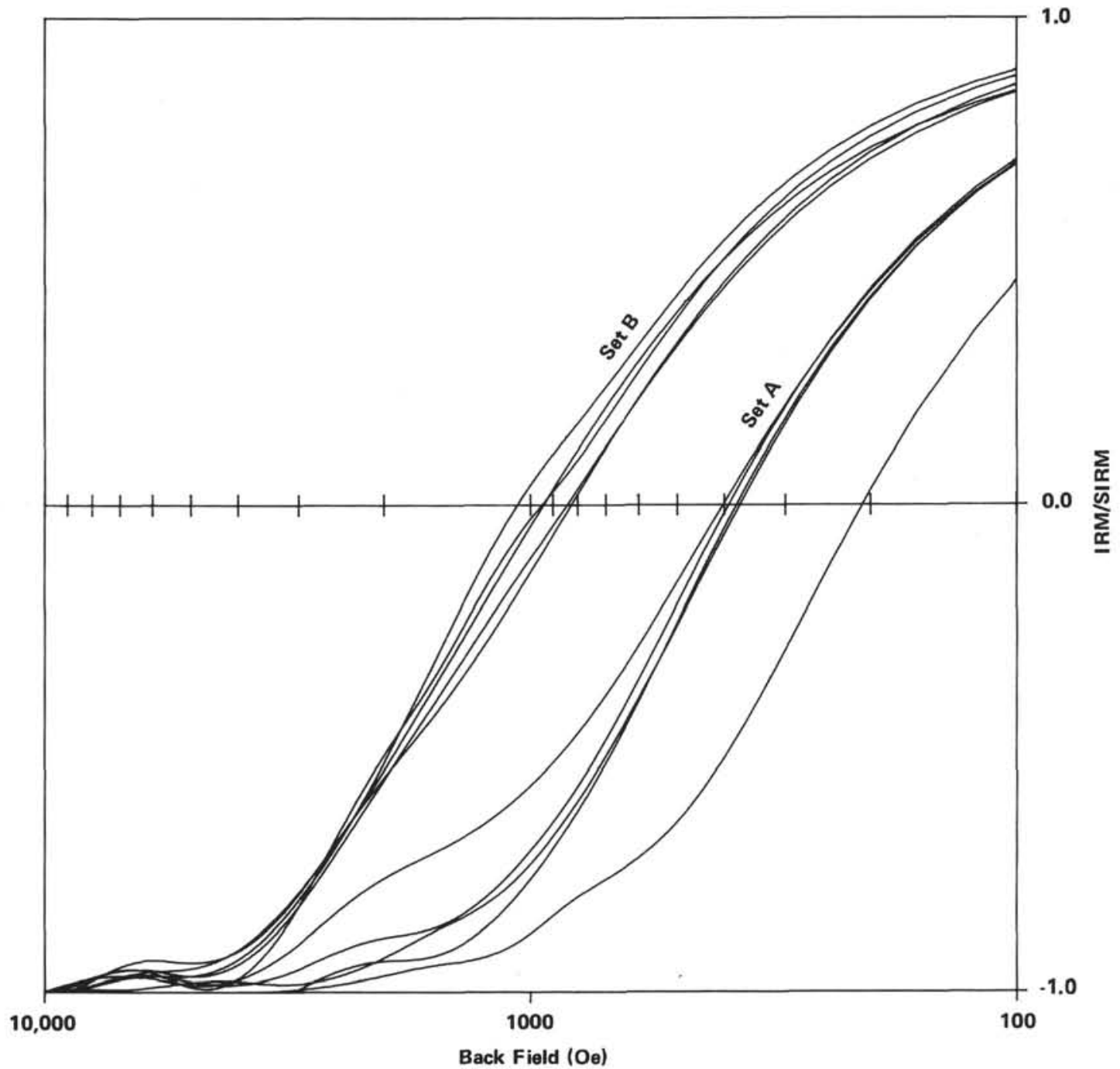

Figure 6. Coercivity of SIRM curves for selected samples from Site 514. Set A. Samples from maxima in magnetic concentration. Set B. Samples from minima in magnetic concentration.

samples which on the basis of their $H_{c r}$ and $S$ values have a significant hard magnetic component, the NRM still resides in a spectrum of grains possessing much lower coercivities.

\section{DISCUSSION}

\section{Changes in Magnetic Concentration}

It is considered that these changes in magnetic parameters reflect changes in the rate and types of magnetic minerals supplied to the sediment surface, which in turn are presumed to reflect the nature and sediment dynamics of depositional paleoenvironments. Most studies of magnetic minerals in marine sediments suggest that they are almost entirely of allochthonous origin, usually dominated by fine-grained, slightly oxidized magnetite or titanomagnetite (e.g., Haggerty, 1970; Opdyke et al., 1972; Løvlie et al., 1972; Creer, 1974; Kobayashi and Nomura, 1974). One situation in which authigenesis or diagenesis of magnetic minerals in marine sediments seems to be significant is in the context of slowly accum- ulating pelagic clays. In this case, blurring of the paleomagnetic directional record with increasing depth has been noted and been attributed to maghemization (Kent and Lowrie, 1974) or todokorite formation (Henshaw and Merrill, 1980). In the case of Henshaw and Merrill's cores, a progressive increase in ARM intensity with depth was noted. None of these cases applies to the magnetic record at Site 514 .

Two possible mechanisms controlling the large and abrupt fluctuations in magnetic concentration (Figs. 1 and 2) between ca. 0-10 m and ca. 60-90 meters might be (1) changes in the rate of supply relative to other sedimentary components of magnetic minerals from continental, volcanic, or hydrothermal sources or (2) changes in depositional or erosional processes controlling the rate of supply relative to other sedimentary components of magnetic minerals to the sediment surface.

In view of the depth and possible duration (ca. 30-60 $\left.y .{ }^{3}\right)$ of some of the susceptibility peaks, single volcanic eruptions are excluded as possible sources of increased magnetic input during these periods. Also, the midoce- 


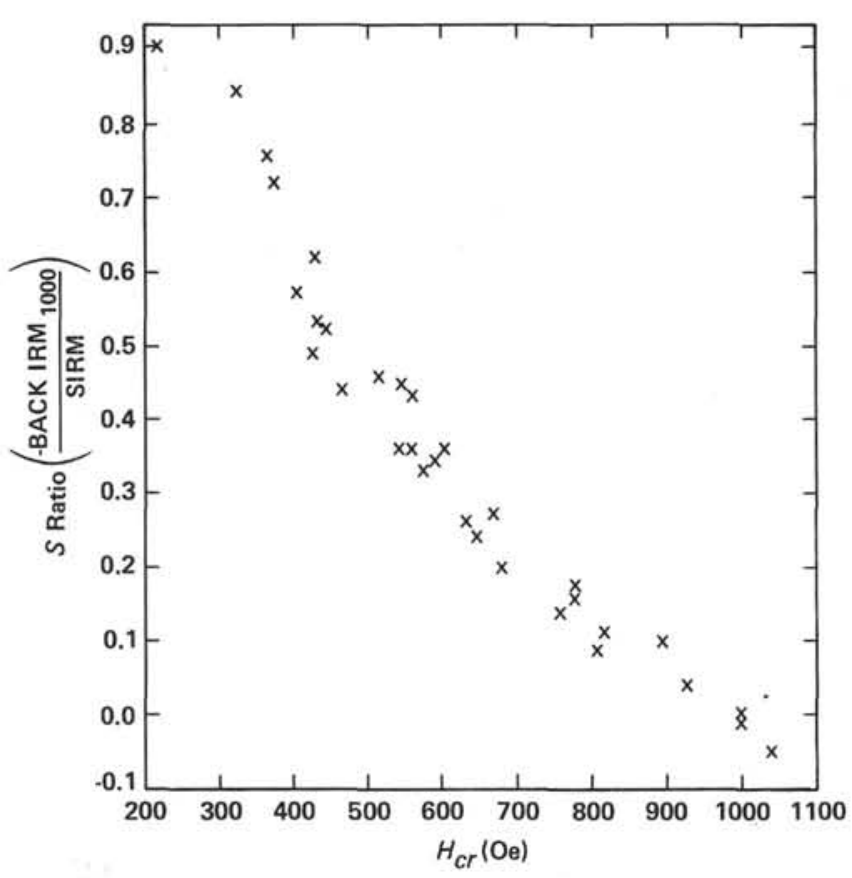

Figure 7. Relationship between $S$-ratio and coercivity of SIRM for samples from Site 514.

anic situation of Site 514 militates against abrupt changes in supply rate of magnetic minerals from continental sources as an explanation. However, support for (2) is provided by evidence from other studies: Ledbetter and Ellwood (1980) illustrate the variation of the mean size of the carbonate-free silt fraction and "Fs" (an anisotropy of susceptibility parameter indicative of the efficiency of alignment of elongated magnetic grains) of surface samples on a transect across the Vema Channel in the South Atlantic. They show that increased values of these parameters correspond to the location of high-velocity Antarctic Bottom Water. They also illustrate the variation of these parameters down Core $\mathrm{CH} 115-62$, from the Vema Channel, and use the fluctuations to infer changes in bottom current paleovelocity. Ellwood (1980) illustrates the variation in magnetic susceptibility of surface samples along the same transect. The variation exhibits a similar trend to that of Fs and silt mean size, with the sample with the highest susceptibility taken from the area subject to Antarctic Bottom Water flow. This suggests a tendency for magnetic minerals to be concentrated relative to other sedimentary components by increased bottom water velocities, presumably by the winnowing of finer particles and/or particles of lower specific gravity, which in turn implies that in some situations changes in magnetic concentration may directly reflect changes in current velocity.

The record of fluctuations in magnetic concentration at Site 514 affords some accordance with Ledbetter and Ellwood's (1980) inferred record of bottom water velocity changes down Core $\mathrm{CH}$ 115-62. Ledbetter and Ellwood (1980) infer a trend of decreasing current velocities above a hiatus (probably partly time-correlative with that at ca. $111 \mathrm{~m}$ at Site 514$)$, interrupted by relatively brief periods of higher velocity flow. Their data for the uppermost Matuyama and Brunhes suggest somewhat increased bottom water velocities during this period.

Assuming that changes in bottom water velocity are generated by climatic change, there is a partial correspondence of the record of magnetic concentration fluctuations at Site 514 with the climatic record for high latitudes of the South Atlantic over the last 4-5 m.y. In their review of the paleoceanographic record of the Maurice Ewing Bank, Ciesielski et al. (1982) consider that general evidence indicates that during the late Gauss (2.95-2.5 Ma) there was a period of climatic amelioration accompanied by a considerable reduction in the vigor of circumpolar oceanic circulation. This accords with the pattern of fluctuations in magnetic concentration of generally declining magnitude at Site 514 during this period. However, they also cite evidence indicating a trend of major global cooling and current intensification beginning around the Gauss/Matuyama boundary (ca. $2.47 \mathrm{Ma}$ ), with an intensification in the upper Matuyama which resulted in nondeposition or erosion on the Maurice Ewing Bank. These changes are not reflected by significant changes in magnetic concentration at Site 514 during this period; however, neither are they reflected in Ledbetter and Ellwood's (1980) inferred record of bottom water velocity changes in Core $\mathrm{CH}$ 115-62. If the association between increased bottom water velocity and increased magnetic concentration is accepted, then it can only be concluded that for some reason climatic deterioration during this period did not induce significant changes in current velocity at Site 514.

\section{Changes in Magnetic Accumulation Rates}

The validity of the plot of magnetic accumulation rate (MAR Fig. 4) is heavily dependent on the accuracy of the age-depth curve (Fig. 3) used to construct it. Assuming that the sharp fluctuations in magnetic concentration at Site 514 result from relatively short-duration increases in bottom water velocity accompanied by winnowing of the fine and/or low specific gravity sediment fractions, it is likely that these periods would also be accompanied by fluctuations in accumulation rate of insufficient duration to be detected by the relatively few age-depth data used to construct Figure 3. If so, then the short-term fluctuations in MAR may be artifactual and reflect temporary reductions in the accumulation rate of the weakly magnetic sediment matrix rather than changes in the rate of supply of magnetic minerals to the sediment surface. Also, the durations of the features obtained from Figure 3 would be minimum estimates of their actual duration. This interpretation is clearly implicit in the winnowing-magnetic concentration mechanism proposed earlier. However, even if we ignore the detailed variations, there still remain significant trends in MAR. The marked fall after ca. $2.5 \mathrm{Ma}$ (ca. $45 \mathrm{~m}$ ) is accompanied by a significant reduction in $\mathrm{Al}_{2} \mathrm{O}_{3} / \mathrm{SiO}_{2}$ (Bornhold, B. D., unpublished data) and by a lithological change from diatomaceous mud to muddy diatomaceous ooze. This suggests a real change in the rate of supply of terrigenous material to the site. 


\section{J. BLOEMENDAL}

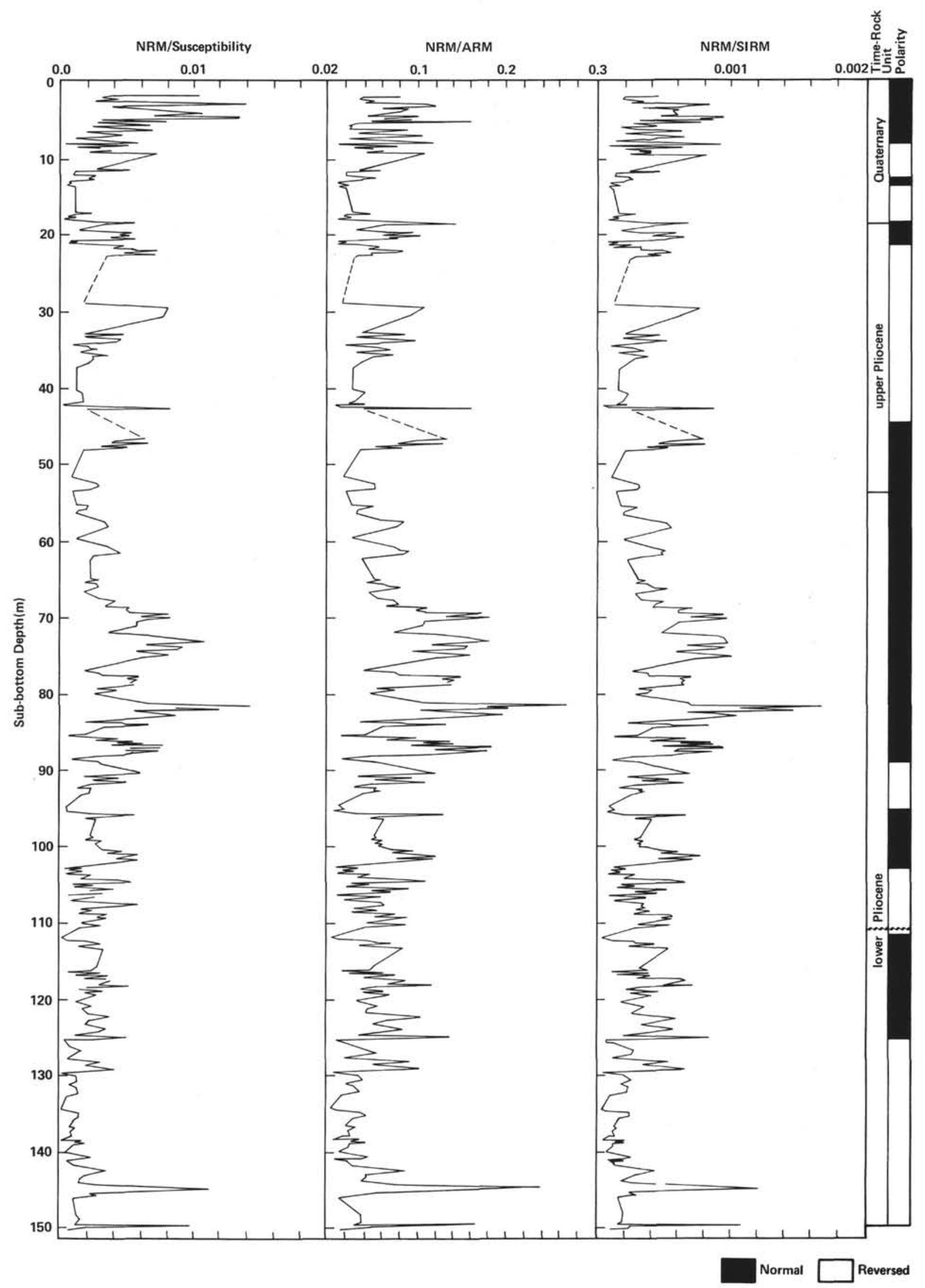

Figure 8. Downhole NRM/susceptibility, NRM/ARM and NRM/ SIRM. 

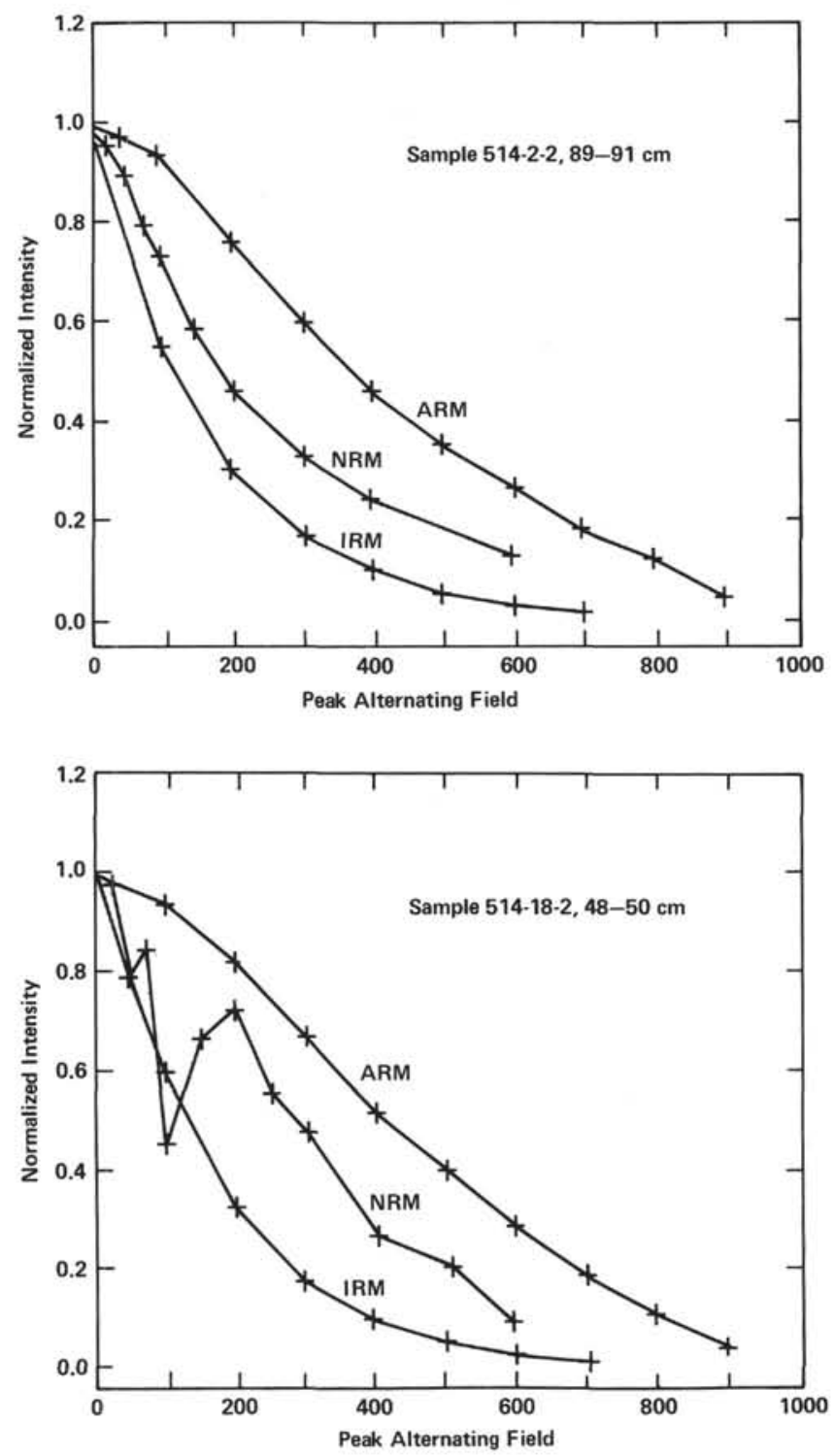

Figure 9. Alternating-field demagnetization curves for selected samples from Site 514.

\section{SUMMARY AND MAIN CONCLUSIONS}

1. The work has demonstrated that potentially valuable paleoenvironmental information can be obtained from the application of simple and rapid mineral magnetic measurements, particularly of volume susceptibility, to the sediments from Site 514 .

2 . At Site 514 , two periods characterized by large fluctuations in magnetic concentration have been identified: from 0 to ca. $0.75 \mathrm{Ma}$ (ca. $0-10 \mathrm{~m}$ ) and from ca. 2.6 to $3.0 \mathrm{Ma}$ (ca. $60-90 \mathrm{~m}$ ). The peaks in magnetic concentration are accompanied by significant reductions in magnetic hardness.

3. The fluctuations in magnetic concentration are tentatively ascribed to changes in current paleovelocity. If this is correct, the sediments from Site 514 contain a highly resolved record of such changes.
4. Changes in NRM intensity at this site are controlled by changes in magnetic content rather than by changes in the intensity of the geomagnetic field. Attempts to normalize the NRM using susceptibility, ARM, and SIRM have been unsuccessful.

\section{ACKNOWLEDGMENTS}

I would like to thank John Salloway for providing me with the NRM data, Dr. K. P. Games for assistance and advice regarding the magnetic measurements, David Owen for computing assistance, and Dr. P. F. Ciesielski for discussion of some of the results. Professor F. Oldfield and Dr. N. Hamilton kindly refereed the paper and suggested several useful improvements. I am particularly grateful to Simon Robinson for his very careful reading of the manuscript and to Mary Main for typing the final draft. I thank the Natural Environment Research Council for financial support.

\section{REFERENCES}

Amin, B. S., Likhite, S. D., Radhakrishnamurty, C., and Somayajulu, B. L. K., 1972. Susceptibility stratigraphy and paleomagnetism of some deep Pacific Ocean cores. Deep Sea Res., 19: 249-252.

Ciesielski, P. F., Ledbetter, M. T., and Ellwood, B. B., 1982. The development of Antarctic glaciation and the Neogene Paleoenvironment of the Maurice Ewing Bank. Mar. Geol., 46:1-51.

Creer, K. M., 1974. Geomagnetic variations for the interval 7000$25000 \mathrm{yr}$ BP as recorded in a core of sediment from station 1474 of the Black Sea cruise of "Atlantis II." Earth Planet. Sci. Lett., 23: 34-42.

Ellwood, B. B., 1980. Induced and remanent magnetic properties of marine sediments as indicators of depositional processes. Mar. Geol., 38:233-244.

Haggerty, S. E., 1970. Magnetic minerals in pelagic sediments. Carnegie Institution Year Book 68: Washington (Geophysical Laboratory, Carnegie Institution), 1560:332-336.

Hamilton, N., 1979. Preliminary magnetic fabric studies of lower Cretaceous sediments from DSDP Site 397, northwest African continental margin. In von Rad, U., Ryan, W. B. F., et al., Init. Repts. DSDP, 47, Pt. 1: Washington (U.S. Govt. Printing Office), 481-482.

Henshaw, P. C., and Merrill, R. T., 1980. Magnetic and chemical changes in marine sediments. Rev. Geophy. Space Phys., 18: 483-504.

Johnson, H. P., Lowrie, W., and Kent, D. V. 1975. Stability of anhysteretic remanent magnetization in fine and coarse magnetite and maghemite particles. Geophys. J. R. Astron. Soc., 41:1-10.

Kent, D. V., and Lowrie, W., 1974. Origin of magnetic instability in sediment cores from the central north Pacific. J. Geophys. Res., 79:2987-3000.

Kobayashi, K., and Nomura, M., 1974. Ferromagnetic minerals in the sediment cores from the Pacific Basin. J. Geophys., 40:501-512.

Ledbetter, M. T., and Ellwood, B. B., 1980. Spatial and temporal changes in bottom-water velocity and direction from analyses of particle size and alignment in deep sea sediment. Mar. Geol., 38: 245-261.

Levi, S., and Banerjee, S. K., 1976. On the possibility of obtaining relative paleointensities from lake sediments. Earth Planet. Sci. Lett., 29:219-226.

Løvlie, R., Lowrie, W., and Jacobs, M., 1971. Magnetic properties and mineralogy of four deep-sea cores. Earth Planet. Sci. Lett., 15:157-168.

Oldfield, F., Dearing, J. A., Thompson, R., and Garrett-Jones, S., 1978. Some magnetic properties of lake sediments and their possible links with erosion rates. Pol. Arch. Hydrobiol., 25:321-331.

Oldfield, F., Rummery, T. A., Thompson, R., and Walling, D. E., 1979. Identification of suspended sediment sources by means of magnetic measurements: some preliminary results. Water Resour. Res., 15:211-218.

Opdyke, N. D., Ninkovich, D., Lowrie, W., and Hays, J. D., 1972. The paleomagnetism of two Aegean deep-sea cores. Earth Plan. Sci. Lett., 14:145-159. 


\section{J. BLOEMENDAL}

Radhakrishnamurty, C., Likhite, S. D., Amin, B. S., and Somayajulu, B. L. K., 1972. Magnetic susceptibility stratigraphy in ocean sediment cores. Earth Planet. Sci. Lett., 4:464-468.

Somayajulu, B. L. K., Walsh, T. J., and Radhakrishnamurty, C., 1975. Magnetic susceptibility stratigraphy of Pacific Pleistocene sediments. Nature, 253:616-617.

Thompson, R., 1980. Palaeomagnetic correlation and dating. In Berglund, B. E. (Ed.), Palaeohydrological Changes in the Temperate
Zone in the Last 15,000 Years. Subproject B. Lake and Mire Environments (Vol. 2): Lund (Department of Quaternary Geology), 39-59.

Wollin, G., Ericson, D. B., and Ryan, W. B. F., 1971. Magnetism of the earth and climatic changes. Earth Planet. Sci. Lett., 29: 219-226. 